\title{
Properties of Some Newly Developed Textile Surgical Sutures
}

\author{
Krishna Kumar $\mathbf{V}^{1}$ and Gokarneshan $\mathbf{N}^{2 *}$ \\ ${ }^{1}$ SMK Fomra Institute of Technology, India \\ ${ }^{2}$ Department of Costume Design and Fashion, SNS Rajalakshmi College of Arts and Science, India \\ *Corresponding author: V Krishna Kumar, SMK Fomra Institute of Technology, Chennai, India
}

\begin{abstract}
The article reviews the recent research trends in textile sutures. Attempt has been made to predict the braiding parameters that can lead to sutures with optimal mechanical performances for specific surgical intervention. The braiding parameters include yarn count and machine settings. Effects of yarn characteristics and machine parameters on a polyamide braid mechanical property have also been studied. Drug loaded PLA suture has been one most potential surgery material to help wounds healing. The loaded drug amounts and sustained drug release effect were a vital part for PLA suture. In this research drug-loaded microspheres and finishing bath were prepared to ensure more drug particles loaded on PLA suture. Moreover, sustained drug release effect and mechanical properties of PLA suture were also observed.
\end{abstract}

Keywords: Textile sutures; polylactic acid; drug release; mechanical properties; polyamide braid; prediction model

\section{Introduction}

In surgeries involving ligaments, stents, nerves and sutures, braided sutures are usually used [1,2]. Owing to their outstanding flexibility, knot stability and handling properties, braided multifilament sutures are commonly used compared to monofilaments $[3,4]$. Braided suture manufacturing process is described in literature, but the available data describes only some steps of this process [5-7]. During the past few year's sutures made from polylactic acid fibers has gained importance in surgeries owing to their striking properties like biocompatibility, biodegradability, and harmlessness. PLA sutures could degrade automatically and be assimilated by body along with wound healing, so it is not necessary to take the stitches out, which made the patients escape from the pain of removing stitches secondary [8-10]. Therefore, PLA sutures were especially suitable for operations towards internal organs and some special positions and occasions, such as episiotomy, circumcision, infant skin closure, as well as infected or polluted wound surfaces [11-13].

\section{Studies on Mechanical Performances of Braided Polyamide Sutures}

The information relating to production factors of braided suture is scanty. This is more particularly so regarding the production factors on tensile properties of suture. A circular braiding machine is used to produce braided sutures. Today's braiding machines still employ the principles of earlier machines. Each sheet yarn is individually controlled by carriers of bobbin that moves along a predetermined path causing yarns interlacement and form braid structure [5,14]. The different interlacing patterns are accomplished by varying the motions of the carriers. There are three of typical tubular braided patterns, viz. diamond, regular and Hercules [15]. Regular tubular braid is normally selected so as to get suture having very small diameters and smooth surface. The geometry of a braided suture is linked to many variables, including braid angle, diameter, and pick count. Braid angle is defined as half of the angle between the interlacing yarns in the vertical direction. 
It is the most important parameter that determines the cover factor of braided structure. A low carrier speed with high take up speed generates loose braided structures with low braiding angles and, consequently, low cover factor. But high carrier speed and low take up speed give closely packed braided structures having higher braiding angles and better cover factors $[16,17]$.

Despite braiding being a conventional technique in manufacture of sutures, a good deal of efforts has been taken for enhancement of the braided suture properties. Indeed, many sutures exhibit failure after implantation. Helical braided sutures have been developed [14]. These sutures are formed by yarns that intersect inside the braid and are parallel to longitudinal axis of braid. It has been observed that these sutures reveal minimal friction when they penetrate through wound tissue. Suture knot security is also improved in the case of these structures. But, sutures commercially available are still being produced in conventional braiding machine. Owing to technological constraint of helical braiding machine the production of suture having required diameters has not been possible. Other initiatives have focused on producing sutures using tubular braids by varying braiding conditions, such as sheets yarn number, yarn count of sheet yarns and cabled core. Intervals of these various parameters that permit to obtain braids having acceptable strength and surface roughness have been established. It has been observed that smoother surface is obtained by using maximum possible number of filaments and sheet yarns. In fact, filaments with very small diameters that allow the use of a high number of sheet yarns and to obtain compact suture surface have been used. The influence of braiding parameters on some suture performances, such as tensile strength and knot pull strength have been investigated [18]. Available data is limited to few analyses on effect of manufacturing conditions. However, there is no available research showing how to establish relation between manufacturing parameters and suture properties.

In a work, tensile analytical model of braided sutures has been developed in order to predict stress-strain behavior of braided sutures based on braid geometry, braid kinematics, and constituent monofilament properties. The model has accounted for the changes in the braid geometry, including braid angle, diameter, and Poisson's ratio. However, proposed model is limited to tensile strength property and did not consider effect of manufacturing conditions. It has therefore been aimed to develop braided sutures by varying the manufacturing parameters, such as yarn count, take up speed and type of braiding machine and to study the effect of these parameters on suture mechanical properties [19]. Prediction models for the mechanical properties are also developed using linear regression method. Finally, an optimization of these parameters is performed by referring to preferred properties reported in literature and meeting the requirements of the US pharmacopeia for diameter and tensile strength. The main objective of the investigation is to understand the effect of yarn characteristics (yarn count) and machine parameter ( $\mathrm{CR}$, sheet yarn number) on the braid mechanical properties (tensile strength, ultimate tensile strength, extension at break, Youngs modulus and FCD mean). Several braids have been manufactured from different yarns in order to be used as PA 6-6 suture. It is found that the yarn count and sheet yarn number are most significant parameters. Linear regression model is used in order to predict mechanical properties as function of manufacturing conditions. Simultaneous surface plots are then generated in order to optimize mechanical properties of suture. Finally, the conditions permitting to produce optimal sutures having properties which meet the USP requirements related to tensile strength and diameters and better performances than those of marketed sutures have been identified.

\section{Properties of Poly (Lactic Acid) (PLA) Suture Loaded with PLA Microspheres Enclosed Drugs}

In aspect of drug using approaches, to avoid infection or rejection, or to relieve pain or inflammation, oral administration was usually adopted to deliver medicines to the whole body, but this might cause side effects to other organs [20-22]. So, loading specific drugs onto sutures was one direct and efficient targeted drug delivery system for the wound [21-23]. In view of the remarkable properties of PLA and the prominent advantages of drug-loaded sutures, the drug loaded PLA suture had received considerable attention in surgery fields, since appropriate drug loading approach was crucial to make PLA suture work more efficiently during wounds healing [24-26]. Until now diverse drugloaded ways for PLA suture had been investigated and there were mainly the following:

a) The drug could be loaded onto PLA fiber (suture) in the spinning process. Aspirin has been directly added to PLA nanofibers and then prepared drug-loaded PLA sutures by electrospinning method [27]. Such drug-loaded method made the drug release slowly and be assimilated fully along with fiber degradation [28-30]. But drug particles might affect the mechanical properties of PLA fiber and the amount of drug loaded was limited too.

b) The drug could also be absorbed or grafted onto the surface of the fiber. 5- Fu was made to absorb on the surface of PLA fiber and further process of drug release has been discussed [28]. This drug-loaded method by absorption or grafting had little influence on the mechanical properties of PLA fiber, but the amount of loaded drug is limited [29-31]. What was more, the drug release rate was high, which caused drug maldistribution and drug release cycle was relatively short.

c) In addition, the drug could be loaded via the coating of fibers (suture). Triclosan has been put into the coating of suture to reduce the surgical infection of coronary artery [32]. The advantage of such drug loaded way was that the loaded drug amounts were big and the fibers (suture) would 
not be destroyed. However, the coating usually made fibers stiffer, which is that the flexibility of suture decreased [33-35]. Moreover, the drug loaded on the coating of suture generally released unevenly and its release cycle was short too.

d) Besides, drugs could be stuffed into the gaps of yarns with multifilament's or multistrands. immersed the suture in specific drug solution to achieve a drug-loaded effect [36].

This drug-loaded way maintained the mechanical properties of PLA suture and the loaded drug amounts were also relatively big, but its downside was that the drug particles easily dissociated from the suture, which caused drug releasing rapidly $[37,38]$. Considering the defects mentioned above, one new drug loaded mode for PLA suture was designed, as illustrated in Figure 1. Firstly, the PLA microspheres enclosed drugs (PM-Ds), with big drugloaded amount and sustained drug release effect, were prepared by emulsification-solvent evaporation method. And following, these microspheres were further loaded on the yarns of PLA suture which was spun by single- or multi-bundles by dip-padding method. Then, PLA drug-loaded microspheres/PLA suture (PM-Ds/PLA) was prepared. By this drug-loaded approach, the amount of loaded drug was big, and the cycle of drug release was long [39-45].

Moreover, these PM-Ds would not impair the mechanical properties of PLA suture and especially its toughness and flexibility were maintained. The designed drug-loaded method for PLA suture not only increased the loaded drug amounts but also achieved drugcontrolled release. In this research, the preparation technology of PM-Ds was optimized, and three parameters, the concentration of PLA, the dosage of emulsifier and the total dosage of drug and emulsifier, were analyzed to explore their effect on the structure and performances of PM-Ds. Moreover, the effect of two parameters, the ratio of agglutinant to microsphere and concentration of finishing bath, on the loaded amounts of PM-Ds were also observed. And then, the drug-release properties and morphology of PM-Ds/PLA suture were further investigated.

This research had successfully prepared the PLA drug loaded microspheres and its optimal technique was that PLA concentration was $0.03 \mathrm{~g} / \mathrm{mL}$, the amount of emulsifier was $0.3 \mathrm{~g}$, and the total amounts of drug and emulsifier was $3 \mathrm{~g}$. The size of PM-D prepared by optimal technique was small and smooth [46]. The finishing bath was used to make more PM-Ds loaded on PLA suture and its appropriate technique was that the ratio of adhesive to PM-Ds was $55 \%$, concentration of finishing bath was $8 \%$. SEM images showed that a great number of microspheres loaded in the gaps of PLA suture. The drug release period had reached 8 days and achieved an excellent sustained drug release effect. Moreover, the flexibility and strength of PLA suture were also maintained after disposal.

\section{Conclusion}

The braiding parameters of braided polyamide sutures have been predicted for optimal mechanical performances in the case of specific surgical intervention. In considering the mechanical performance yarn count and sheet yarn number have proved to be the most significant factors. Predictive models of the suture mechanical responses based on yarn characteristics and machine parameters have been developed and it shows very significant level. Using simultaneous contours plots, manufacturing conditions permitting to obtain optimal mechanical properties meeting the requirements of the US Pharmacopeia for the diameter and tensile strength are determined for sutures having USP number from 3-0 to 2. Drug-loaded microspheres and finishing bath were prepared to ensure more drug particles loaded on PLA suture. Moreover, sustained drug release effect and mechanical properties of PLA suture were also observed. The results suggested that PLA concentration and emulsifier amounts had more effect on the size of PLA drug-loaded microspheres and the optimal technology was: $0.03 \mathrm{~g} / \mathrm{mL}$ of PLA concentration, $0.3 \mathrm{~g}$ of amount of emulsifier and the total amount of drug and emulsifier was 3g. Moreover, drug release test showed a significant sustained release effect of the drug-loaded PLA suture. Mechanical measurements indicated the flexibility and strength were not impaired by such drug-loaded method. This research is expected to benefit the surgery fields further.

\section{References}

1. Rajendran S, Anand SC (2001) Textile progress. 32(2).

2. Marzougui S, Abdessalam SB, Sakley F (2009) Journal of Applied science, 9: 2794 .

3. Hockenberger AS, Karaca E (2004) Indian journal of fibres and textile research, 29: 278.

4. Karaca E, Hockenberger AS (2001) Textile research journal, 71: 435.

5. Daversa M, Scalzo LHJ, Jamiolkowlski DD, Bezwada RS, Hill DG, et al. (2004) Braided suture with improved knot strength and process to produce the same, US Patent 6712838 B2.

6. Hutton JD, Dumican BL (2001) Braided polyester suture and implanted medical device, US Patent 62303564 B1.

7. Pokropinski H, Scalzo H, Fischer JA (2002) Process for making sutures having improved knot tensile strength US Patent 6881434 B2.

8. Lou CW, Yao CH, Chen YS, Hsieh TC, Lin JH, et al. (2008) Manufacturing and properties of PLA absorbable surgical suture. Textile Research Journal 78(11): 958-965.

9. Prahsarn C, Klinsukhon W, Padee S, Suwannamek N, Roungpaisan N, et al. (2016) Hollow segmented-pie PLA/PBS and PLA/PP bicomponent fibers: An investigation on fiber properties and splittability. Journal of Materials Science 51(24): 10910-10916.

10. Vieira AC, Medeiros R, Guedes RM, Marques AT, Tita V (2012). Viscoelastic-plastic properties of suture fibers made of PLA-PCL. Materials Science Forum 730(732): 56-61.

11. Armentano I, Bitinis N, Fortunati E, Mattioli S, Rescignano N, et al. (2013) Multifunctional nanostructured PLA materials for packaging and tissue engineering. Progress in Polymer Science 38(10-11): 1720-1747.

12. Sui XW, Wang S (2017) Study on spinning process and constant tension control system of absorbable suture. Chinese Journal of Sensors and Actuators 30: 157-161.

13. Zhang LJ, Song JJ, Wang WH (2016) The application of self-fixed barbed wire absorption suture in laparoscope cholelithotomy. Journal of Medical Theory \& Practice 29: 2040-2042. 
14. Chesterfield MP, Koyfman IS, Kaplan DS, Hermes ME (1993) Cabled core and braided suture made therefrom, US Patent 5261886.

15. Liu GH, Hu H, Zhang PH, Wang WZ (2006) Journal of Industrial Textiles 36: 35 .

16. Rana S, Fanguiero R (2016) Braided structures and composites: Production, properties, mechanics and technical applications (Taylor and Francis group, New York, USA) pp. 317.

17. Potluri P, Rawal A, Rivaldi M, Porat I (2003) Composite Part A Applications, 34: 481.

18. Kaplan DS, Hermes ME, Muth RR (1994) Braided suture of improved characteristics, US Patent 5306289.

19. Faten D, Saber Ben A (2018) Modeling and experimental investigation of mechanical performances of braided polyamide sutures. Indian journal of fibres and textile research 43: 186-193.

20. Matsuda T, Iwasaki T, Mitsutsuji M, Hirata K, Maekawa $\mathrm{Y}$, et al. (2015) Surgical outcomes of intracorporeal circular-stapled esophagojejunostomy using modified over and over suture technique in laparoscopic total gastrectomy. Surgical Ndoscopy 29(11): 3386-3391.

21. Terasaka S, Taoka T, Kuroda S, Mikuni N, Nishi T, et al. (2017) Efficacy and safety of non-suture dural closure using a novel dural substitute consisting of polyglycolic acid felt and fibrin glue to prevent cerebrospinal fluid leakage-A non-controlled, open-label, multicenter clinical trial. Journal of Materials Science - Materials in Medicine 28: 1-9.

22. Zhang LJ, Song JJ, Wang WH (2016) The application of self-fixed barbed wire absorption suture in laparoscope cholelithotomy. Journal of Medical Theory \& Practice 29: 2040-2042.

23. Buezo O, Cusc_OX, Seijas R, Sallent A, Ares O, et al. (2015) An innovative surgical technique with transosseous suture to avoid implant removal. Surgical Innovation 22(5): 474-478.

24. Kanamala M, Wilson WR, Yang M, Palmer BD, Wu Z (2016) Mechanisms and biomaterials in pH-responsive tumour targeted drug delivery: A review. Biomaterials 85: 152-167.

25. Vries de JW, Schnichels S, Hurst J, Strudel L, Gruszka A, et al. (2018) DNA nanoparticles for ophthalmic drug delivery. Biomaterials 157: 98-106.

26. Hu Y, Darcos V, Monge S, Li S (2015) Thermo-responsive drug release from self-assembled micelles of brush-like PLA/PEG analogues block copolymers. International Journal of Pharmaceutics 491(1-2): 152-161.

27. Meunier M, Goupil A, Lienard P (2017) Predicting drug loading in PLAPEG nanoparticles. International Journal of Pharmaceutics 526(1-2): 157-166.

28. Sungkapreecha C, Iqbal N, Gohn AM, Focke WW, Androsch R (2017) Phase behavior of the polymer/drug system PLA/DEET. Polymer 126: 116-125.

29. Qin JW, Jiang YY, Fu JJ, Wan YQ Yang RH, et al. (2013) Evaluation of drug release property and blood compatibility of aspirin-loaded electrospun PLA/RSF composite nanofibers. Iranian Polymer Journal 22(10): 729737.

30. Khodaverdi E, Aboumaashzadeh M, Tekie FSM, Hadizadeh F, Tabassi SAS et al. (2014) Sustained drug release using supramolecular hydrogels composed of cyclodextrin inclusion complexes with PCL/PEG multiple block copolymers. Iranian Polymer Journal 23(9): 707-716.

31. Prabhakar MN, Rao US, Babu PK, Subha MCS, Rao KC (2013) Interpenetrating polymer network hydrogel membranes of PLA and SA for control release of penicillamine drug. Indian Journal Advanced Chemical Sciences 1: 240-249.
32. Thimour Bergstreom L, Roman Emanuel C, Scherst_En H, Friberg EO, Gudbjartsson T, et al. (2013) Triclosan-coated sutures reduce surgical site infection after open vein harvesting in coronary artery bypass grafting patients: A randomized controlled trial. European Journal of Cardio-Thoracic Surgery 44(5): 931-938.

33. Thomasin C, Merkle HP, Gander B (1998) Drug microencapsulation by PLA/PLGA coacervation in the light of thermodynamics. 2. Parameters determining microsphere formation. Journal of Pharmaceutical Sciences 87(3): 269-275

34.Xu WJ, Yang YQ, Xu WJ, Yang YQ (2010) Relationship between drug release and some physical parameters of drug sorption onto PLA fibers. Journal of Biomaterials Science Polymer Edition 21(4): 445-462.

35. Lim WS, Chen K, Chong TW, Xiong GM, Birch WR, et al. (2018) A bilayer swellable drug-eluting ureteric stent: Localized drug delivery to treat urothelial diseases. Biomaterials 165: 25-38.

36. Wischke C, Schwendeman SP (2008) Principles of encapsulating hydrophobic drugs in PLA/PLGA microparticles. International Journal of Pharmaceutics 364(2): 298-327.

37.Zhong J, Li L, Zhu X, Guan S, Yang Q, et al. (2015) A smart polymeric platform for multistage nucleus-targeted anticancer drug delivery. Biomaterials 65: 43-55

38. Jelonek K, Li S, Kaczmarczyk B, Marcinkowski A, Orchel A, et al. (2016) Multidrug PLA-PEG filomicelles for concurrent delivery of anticancer drugs-the influence of drug-drug and drug-polymer interactions on drug loading and release properties. International Journal of Pharmaceutics 510(1): 365-374

39. Stadler S, Fleck T (2011) Triclosan-coated sutures for the reduction of sternal wound infections: A retrospective observational analysis. Interactive Cardiovascular and Thoracic Surgery 13(3): 296-299.

40. Steingrimsson S, Thimour Bergstreom L, Roman Emanuel C, Scherst en H, Friberg €O, et al. (2015) Triclosan-coated sutures and sternal wound infections: A prospective randomized clinical trial. European Journal of Clinical Microbiology \& Infectious Diseases 34: 2331.

41. Qu Y, An F, Luo Y, Lu Y, Liu T, et al. (2018) A nephron model for study of drug-induced acute kidney injury and assessment of drug-induced nephrotoxicity. Biomaterials 155: 41-53.

42. Andres Guerrero V, Zong M, Ramsay E, Rojas B, Sarkhel S, et al. (2015) Novel biodegradable polyesteramide microspheres for controlled drug delivery in ophthalmology. Journal of Controlled Release 211: 105-117.

43. Cho H, Gao J, Kwon GS (2016) PEG-b-PLA micelles and PLGA-b-PEGb-PLGA sol-gels for drug delivery. Journal of Controlled Release 240: 191-201.

44. Papa A, Korin N, Kanapathipillai M, Mammoto A, Mammoto T, et al. (2017) Ultrasound-sensitive nanoparticle aggregates for targeted drug delivery. Biomaterials 139: 187-194.

45. Viinikainen AK, Georansson H, Huovinen K, Kellomeaki M, Teormealea P, et al. (2009) Bioabsorbable poly-L/D-lactide (PLDLA) 96/4 triplestranded bound suture in the modified Kessler repair: An ex vivo static and cyclic tensile testing study in a porcine extensor tendon model. Journal of Materials Science - Materials in Medicine 20(9): 1963-1969.

46. Shuqiang L, Gaihong W, Xiaofang Z, Juanjuan Y, Mingfang L, et al. (2019) Preparation and properties of poly (lactic acid) (PLA) suture loaded with PLA microspheres enclosed drugs (PM-Ds). The Journal of The Textile Institute 110(11): 1-10. 
This work is licensed under Creative Commons Attribution 4.0 License

To Submit Your Article Click Here: Submit Article

DOI: $10.32474 /$ SJ0.2020.04.000195

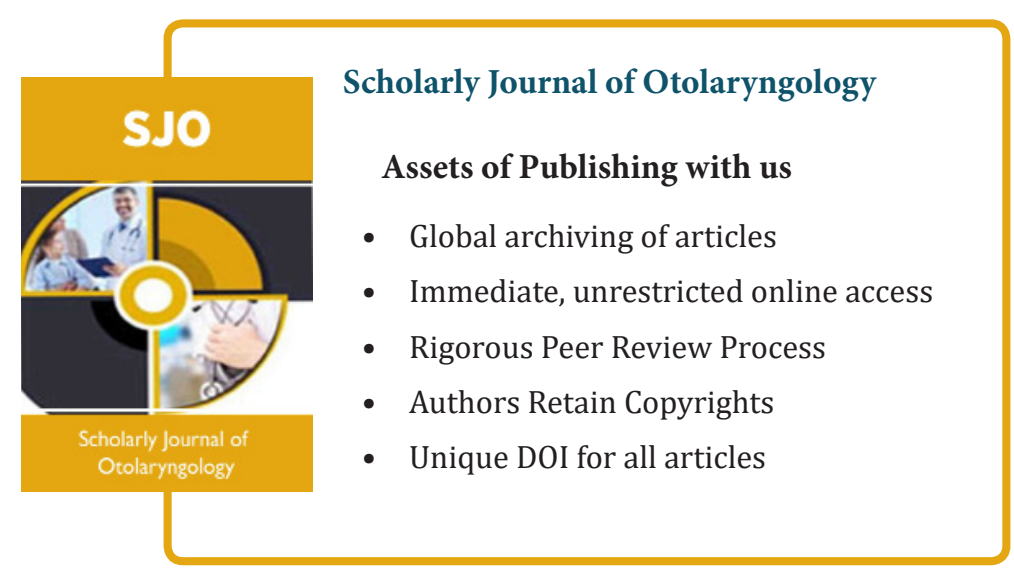

